Research Article

\title{
Study on Fatigue Characteristics of Carbonation Erosion Prestressed Hollow Slabs in Whole Life Cycle
}

\author{
Yuanxun Zheng, ${ }^{1,2}$ Kuan Li ${ }^{1},{ }^{1}$ Mengen Ji, ${ }^{2}$ and Ehsan Moshtagh ${ }^{3}$ \\ ${ }^{1}$ School of Water Conservancy Science and Engineering, Zhengzhou University, Zhengzhou, Henan 450001, China \\ ${ }^{2}$ Henan Transport Investment Group Co. Ltd., Zhengzhou, Henan 450000, China \\ ${ }^{3}$ School of Civil Engineering, College of Engineering, University of Tehran, P.O. Box 11155-4563, Tehran, Iran
}

Correspondence should be addressed to Kuan Li; lkzzu@gs.zzu.edu.cn

Received 23 April 2020; Accepted 3 August 2020; Published 17 August 2020

Academic Editor: Chiara Bedon

Copyright (c) 2020 Yuanxun Zheng et al. This is an open access article distributed under the Creative Commons Attribution License, which permits unrestricted use, distribution, and reproduction in any medium, provided the original work is properly cited.

\begin{abstract}
In this paper, the whole life cycle (failure-reinforcement-failure) durability and related fatigue properties of prestressed hollow beam under carbonation erosion environment were studied. According to a $20 \mathrm{~m}$ hollow slab beam, the model of prestressed hollow beam was designed and made, and the durability and fatigue tests for the whole life cycle of prestressed hollow beam were carried out. The results showed that the compressive strength and elastic modulus of the specimens increased by about $20 \%$ under the action of carbonization erosion. With the increase of fatigue loading cycles, the crack occurrence and development speed of carbonized erosion components were greater than those of healthy components, and the fatigue life decreased sharply from 3 million cycles to 50,000 cycles. Pasting carbon fiber and steel plate had better reinforcement effect on the damaged prestressed plate beam and could help improving the fatigue life of the reinforced component. Comparing the reinforcement of different strengthening methods, it is found that the steel-plate-reinforced components have better mechanical properties and antifatigue attenuation characteristics than the carbon-fiber-reinforced ones. The research results have important theoretical value for improving the durability of structure and prolonging its service life.
\end{abstract}

\section{Introduction}

With the continuous worsening of environmental problems, the effects of adverse environmental factors such as chloride ion penetration, carbonization, and freeze-thaw cycles on bridge structure have become increasingly severe, thus resulting in widespread early damage of the in-service bridge. While increasing the expensive repair and reinforcement costs, the durability of the bridge structure is also greatly reduced, and which results in the shortening of the structural fatigue life and reduction in the service life for bridge structure. Under the action of vehicle loads and adverse environmental erosion, after the damage (environmental damage + fatigue damage), the reinforcement bridge structure also experiences durability deterioration. At present, the main evaluation criterion for bridge reinforcement is whether the bearing capacity (bending, shear resistance, etc.) of the reinforced components meets the design requirements, and the durability and fatigue life of the reinforced components are not included in the specification. The studies show that some reinforcement bridges lose its reinforcement effect in a short period of time owing to the deterioration of the durability of the reinforcement. And which would cause large economic losses and also result in major safety accidents.

Early research studies on structural durability mainly paid attention on concrete materials [1-3]. The standard concrete specimens were mainly used to study the durability degradation mechanism under adverse environmental conditions, for example, the concrete carbonation mechanism and model. The effects of chloride ions [4] and sulfate attack on the durability of concrete members [5-7] and the analysis of steel corrosion caused by carbonization were also established. Based on the study on the durability of concrete 
materials, scholars began to attempt to improve the durability of concrete structures from design perspective, and the research results at this stage mainly focused on the durability design and evaluation of concrete structures [8, 9]. Jin et al. [10], based on the definition of concrete structure durability, proposed that the durability design should combine the concept of structural full life cycle cost and established a life assessment system on the basis of the dynamic evaluation method. Berger et al. [11] proposed a new concept for improving the durability of concrete, which is improved by the use of plastic treatment on the external surface of the concrete. Nganga et al. [12] proposed the concept of a structural durability evaluation index based on experimental research and practical engineering. Lotfy et al. [13] studied the durability of three graded, lightweight, self-compacting concretes. In the study on the durability design method and evaluation method of concrete structures, it has been found that adding appropriate fibers into concrete materials can improve the durability of concrete structures, and related research has been conducted [14-17]. In recent years, research on the durability of bridge concrete structures based on the mesoscale has also been conducted $[18,19]$. For the research on carbonized erosion concrete structures, Jiang et al. [20] analyzed the coupling effect of fatigue load and carbonation on concrete from the material level and established a concrete carbonation life prediction model under the combined action of fatigue load and atmospheric environment. Zhao et al. [21] studied the carbonation resistance of concrete subsequent to stress damage and highlighted that stress damage has a significant influence on the carbonation life of concrete. Lu [22] analyzed the influence of carbonation corrosion on the bearing capacity degradation of bridges and predicted the bearing capacity of bridge concrete carbonation during the design period. $\mathrm{Li}$ studied the bond behavior between steel and concrete under repeated loading and established the constitutive relationship between the bond properties of steel and fully carbonized concrete under repeated loading. Neves et al. [23] used the rapid carbonization test to develop and propose a semiprobabilistic design theory of concrete structure life under carbonization. Arredondo-Rea et al. [24] studied the effect of carbonation depth on the corrosion rate of steel in reinforced concrete.

With the occurrence of engineering accidents caused by the deterioration in durability of reinforcement bridges, the durability problem for bridge reinforcement has gradually attracted the attention of the academic community, and related research has also been conducted. The early research was mainly conducted to determine the durability of the reinforcing material and binder. Wang et al. [25] found that seawater corrosion has a negligible effect on the physical properties of fiber-reinforced plastic (FRP) materials, and the carbon-fiber-reinforced polymer concrete (CFRP-concrete) bonding strength decreases as the corrosion time increases. Yin [26] studied the effect of chloride salt erosion on the mechanical properties and durability of CFRP. Yan and Lin [27] studied the durability decay law and prediction model of a bonded surface of glass-fiber-reinforced columns under solution erosion. Altalmas et al. [28] analyzed the decay interface of basalt-fiber-reinforced beams in an accelerated aging environment. At present, the relevant scholars at home and abroad have conducted research on the fatigue performance of reinforced concrete structures strengthened using the method of pasting a steel plate and carbon fiber cloth. Zhang et al. [29] conducted an experimental study on the bending fatigue behavior of reinforced concrete beams strengthened using prestressed carbon fiber sheets. It was concluded that the midspan deflection and top compressive strain of the strengthened test beams were significantly reduced. Chen and $\mathrm{Lu}$ [30] studied the fatigue performance of the normal section of reinforced concrete beams strengthened using carbon fiber sheets. It was concluded that the carbon fiber cloth inhibited the development of cracks to limited extent and improved the stiffness of the test beams. Zhang et al. [31] studied the effects of carbon fiber cloth reinforcement, damage degree before loading, load ratio, and steel corrosion rate on the bending fatigue performance of corroded reinforced concrete beams strengthened by carbon fiber cloth. Capozucca and Nilde Cerri [32] studied the deformation characteristics and fatigue strength of carbon-fiber-reinforced concrete beams. As compared with the unreinforced beams, the deflection and crack width of the strengthened test beams were reduced, and the static load ultimate bearing capacity of the test beams was significantly improved. Both the carbon fiber board and the bonded steel sheet could improve the fatigue performance of the reinforced concrete structure. Gheorghiu et al. [33] studied the degradation law of the fatigue process of reinforced concrete beams strengthened by carbon fiber sheets. In the case of the fatigue performance of a bonded steel plate reinforcement structure, Gan [34] analyzed the mechanism involved the use of an anchorage steel plate to improve the bearing capacity of reinforced concrete beams and proposed the calculation formula for the shear capacity of concrete beam. Zhang et al. [35] studied the fatigue characteristics of reinforced concrete beams strengthened using the bonded steel plate method and the carbon fiber cloth method. It was found that the sticking steel plate method could improve the stiffness of the beam than the carbon fiber method. However, its fatigue life was shorter than that of the bonded carbon fiber cloth method. Zhai et al. [36] conducted static and fatigue tests on the reinforced concrete beams with different strength grades and found that the thicker the reinforcement of the bottom steel plate, the more the stiffness was improved owing to the resulting strengthening. When the concrete member with higher strength was bonded to a steel plate method, the fatigue performance was improved.

Based on recent literature studies at home and abroad, it can be found that the early research on the durability of concrete was mainly focused on the study of the material durability. As research has progressed, a transition has occurred to the optimization of structural durability and improvement of durability by adding fibers, and the influencing factors gradually transitioned from a single erosion environment to multifactor coupling. In the literature on structural reinforcement, it was found that the current structural reinforcement method was mainly applicable to 
assess reinforcement structural bearing capacity. The evaluation criterion was whether the structural bearing capacity can meet the design requirements after reinforcement. However, the durability and fatigue requirements were not required. Few studies have been focused on the characteristics of durability after damaged structure reinforcement, and especially the fatigue performance of reinforced concrete slabs under environmental corrosion conditions. Therefore, based on the principle of similarity and in combination with the actual bridge structural parameters, $2 \mathrm{~m}$ long prestressed hollow slab beam model was designed and fabricated. The carbonized erosion tests were performed in the modified rapid carbonization tank to study the influence of carbonization erosion on the fatigue characteristics of a prestressed hollow slab and reinforced prestressed hollow slab beam. The durability index and structural fatigue characteristics of prestressed slab beam under carbonization erosion were established. The research results have important theoretical and engineering significance for revealing the mechanical properties of concrete materials under carbonization erosion, clarifying the entire life cycle durability decline mechanism of bridge structures under carbonization and its relationship with the fatigue characteristics, and optimizing bridge structure reinforcement schemes.

\section{Experimental Design}

Based on the similarity principle [37], according to the structural parameters of $20 \mathrm{~m}$ highway prestressed hollow slab bridge widely used in engineering, $2 \mathrm{~m}$ long prestressed hollow slab beam model was designed and fabricated. The similarity coefficient of the prestressed concrete test slab is presented in Table 1. The pretensioned construction method was adopted, and the concrete strength grade was C50. The longitudinal prestressed steel bars were three 1860 grade steel strands with a diameter of $12.7 \mathrm{~mm}$, the cross-sectional area was $98.7 \mathrm{~mm}^{2}$, and the prestressed tension was $1395 \mathrm{MPa}$. The test plate transverse, longitudinal section, and reinforcement are shown in Figure 1.

In consideration of the carbonization test member length is $2 \mathrm{~m}$, the durability test cannot be performed in the tradition rapid carbonization tank. According to the "Standards for Long-Term Performance and Durability Test Methods for Conventional Concrete" [38], a kind of rapid carbonization test equipment was designed to perform the durability test [39], and the test setup is shown in Figure 2.

The carbonation corrosion test design and postloading conditions of prestressed concrete hollow slabs are presented in Table 2.

\section{Experiment}

3.1. Carbonization Erosion of Standard Test Specimen. Standard specimens were used to determine the depth of the carbonation erosion and could also provide a reference for studying the effects of carbonation erosion on the mechanical properties of concrete structures. In this study, the carbonation depth measurement was performed on the standard specimen for a certain period of carbonization erosion and using the phenolphthalein test method. The test of the compressive strength and elastic modulus of the uncarbonized specimens, mildly carbonized specimens, and severely carbonized specimens were performed. The test results were used to study the effect of carbonation erosion on the mechanical properties of concrete.

\subsection{Experimental Study on Influence of Carbonation Erosion on Fatigue Characteristics of Prestressed Hollow Slab Beams}

3.2.1. Static Load Test of Prestressed Hollow Slab. The static load test was mainly used to determine the ultimate bearing capacity, failure mode, and deformation characteristics of the slab beam. The determination of fatigue test loading stress amplitude and load value is also based on the static load failure test results. The static load test was performed using a microcomputer-controlled electrohydraulic servo bending tester. The loading device is shown in Figure 3.

\subsubsection{Fatigue Failure Test of Prestressed Hollow Slab Beam} under Carbonization Erosion. The fatigue test was performed of different carbonization erosion degree hollow slab beams by the method of three-point loading. The loading mode is shown in Figure 4. Based on the static load test results, the fatigue loading stress amplitude was determined as 0.8 , and the fatigue test loading scheme is shown in Table 3.

\subsection{The Influence of Carbonation Erosion on the Fatigue Characteristics of Prestressed Hollow Slab Beams}

3.3.1. Fatigue Precracking Treatment of Prestressed Hollow Slab. To obtain the prestressed hollow slab which suffered fatigue damage, the fatigue preloading treatment for healthy prestressed hollow plate was required. According to the static load destructive test, the ultimate bearing capacity of the test plate was determined to be $245 \mathrm{kN}$. Based on the stress ratio of 0.8 , the upper and lower limits of the fatigue are approximately $200 \mathrm{kN}$ and $50 \mathrm{kN}$, respectively. To ensure the uniformity damage state of all test plates, the crack width was used as the control index, and fatigue loading was applied until the crack width was approximately $0.2 \mathrm{~mm}$.

\subsubsection{Reinforcement Scheme for Prestressed Hollow Slab.} The carbon fiber cloth reinforcement and bonding steel plate reinforcement technology do not change the stress system and structural form of the original component and can effectively improve the structural bearing capacity and rigid fracture performance, and are widely used in reinforced engineering. In this experiment, two types of reinforcement methods were applied to reinforce the damage components. The strengthened components are shown in Figure 5.

\subsubsection{Static Load Failure Test of Reinforced Prestressed} Hollow Slab. To verify the reinforcement effect of the bonded steel plate and carbon-fiber-cloth-reinforced test 
TABLE 1: Similarity coefficient of the test plate.

\begin{tabular}{lccccc}
\hline $\begin{array}{l}\text { Physical } \\
\text { quantity }\end{array}$ & $\begin{array}{c}\text { Poisson's ratio for } \\
\text { concrete } \mu_{c}\end{array}$ & $\begin{array}{c}\text { Elastic modulus of } \\
\text { concrete } E_{c}(\mathrm{kPa})\end{array}$ & $\begin{array}{c}\text { Elastic modulus of prestressed } \\
\text { steel bundle } E_{s}(\mathrm{kPa})\end{array}$ & $\begin{array}{c}\text { Length of test } \\
\text { plate } l(\mathrm{~m})\end{array}$ & $\begin{array}{c}\text { Cross-sectional area of } \\
\text { test plate } A(\mathrm{~m})\end{array}$ \\
\hline Similarity & $c_{\mu_{c}}=1$ & $c_{E_{c}}=1$ & $c_{E_{s}}=1$ & $c_{l}=0.01$ & $c_{A}=0.25$ \\
\hline
\end{tabular}

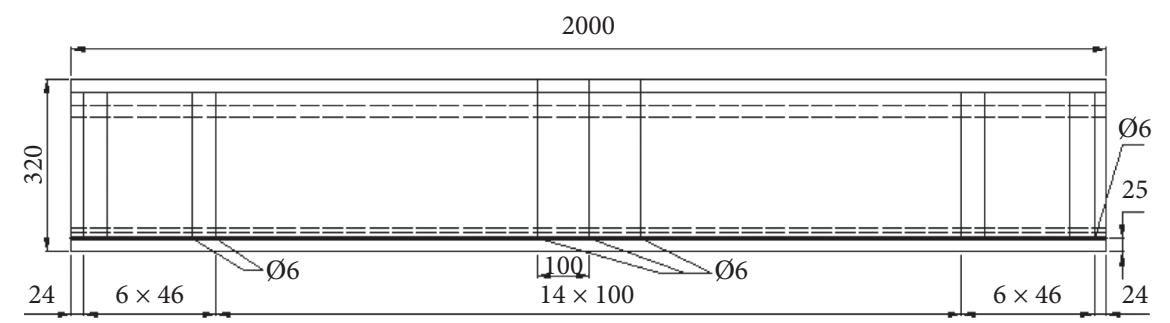

(a)

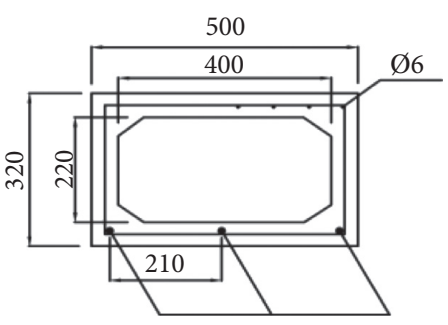

$\varnothing 12.7$ prestressed steel strand

(b)

Figure 1: Cross section, longitudinal section, and bar arrangement drawing of test plate: (a) longitudinal section and (b) cross section.

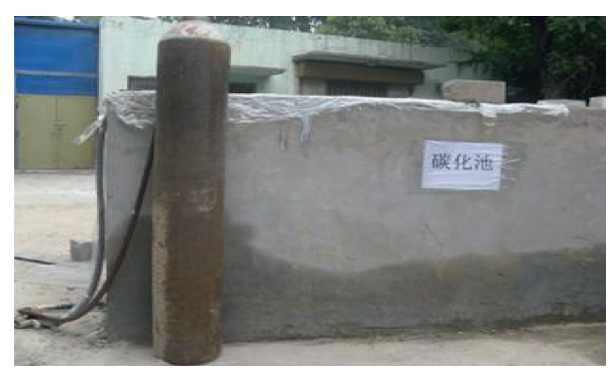

FIgURe 2: Modified carbonized corrosion device.

TABLE 2: Carbonation corrosion design and loading methods.

\begin{tabular}{lcc}
\hline Test board number & Degree of carbonization & Loading conditions \\
\hline B-0 & Healthy component & Static load \\
BW & Uncarbonized corrosion member & Fatigue \\
BQ & Mild corrosion (carbonization depth $5 \mathrm{~mm}$ ) & Fatigue \\
BZ & Heavy corrosion (carbonization depth $10 \mathrm{~mm}$ ) & Fatigue \\
\hline
\end{tabular}

Note. Each group plates in Table 2 comprise two components. For example, BQ included two components, BQ-1 and BQ-2. The average value of the two components was taken as the test value of the group.

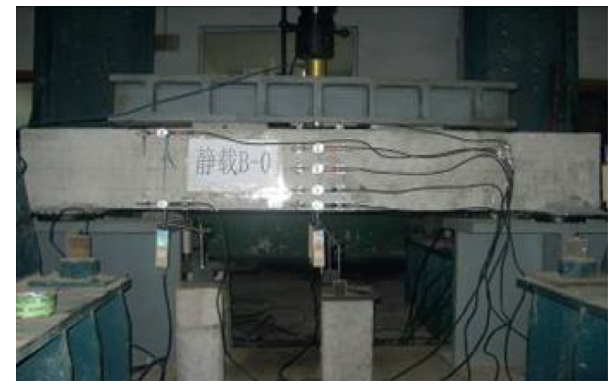

Figure 3: Static load test of the prestressed hollow beam.

plate, the static test was performed on the plates before and after reinforcement, and the mechanical properties of the test plates before and after reinforcement were analyzed. The test was performed by the three-point loading method. The length of the test plate was $2000 \mathrm{~mm}$, its net span was $1900 \mathrm{~mm}$, and rubber bearings were used at both ends. Considering the difference in the bearing capacity before and after the reinforcement, the maximum load of the test plate was determined to be $150 \mathrm{kN}$, the loading device was a kind of 25-ton multifunctional hydraulic testing machine, and an I-beam was used as the guide beam to transmit the load. The static load test process measurements mainly include the load, deflection, and strain measurements. The loading equipment is shown in Figure 6.

3.3.4. Fatigue Failure Test of Reinforced Prestressed Hollow Slab. Firstly, the fatigue characteristic test was performed on the test plate without carbonization corrosion, the test phenomenon during the fatigue test was 


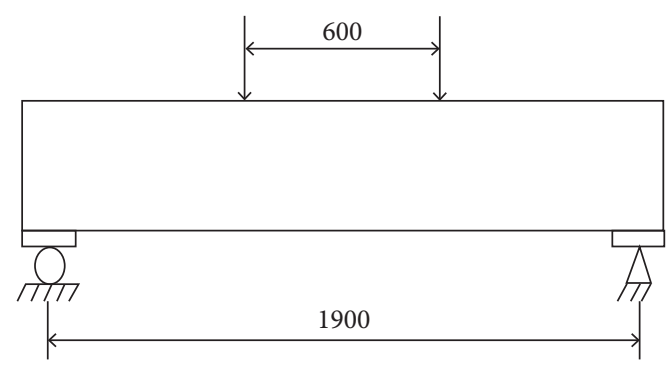

(a)

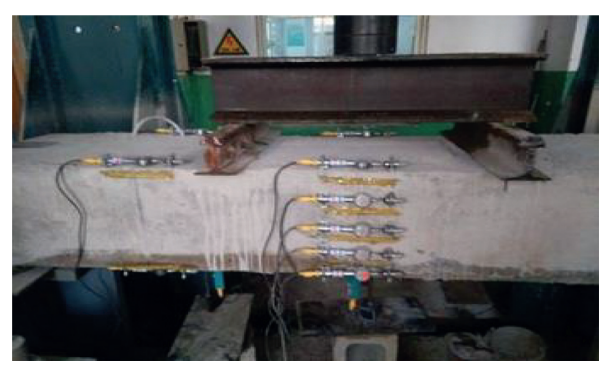

(b)

FIGURE 4: Fatigue loading diagram (units: $\mathrm{mm}$ ): (a) loading diagram (units: $\mathrm{mm}$ ) and (b) fatigue loading (units: $\mathrm{mm}$ ).

TABle 3: Fatigue test scheme.

\begin{tabular}{lccc}
\hline Test piece number & Maximum fatigue load $F_{\max }(\mathrm{kN})$ & Minimum fatigue load $F_{\min }(\mathrm{kN})$ & Frequency $(\mathrm{Hz})$ \\
\hline BW & 200 & 50 & 5 \\
BQ & 200 & 50 & 5 \\
BZ & 200 & 50 & 5 \\
\hline
\end{tabular}

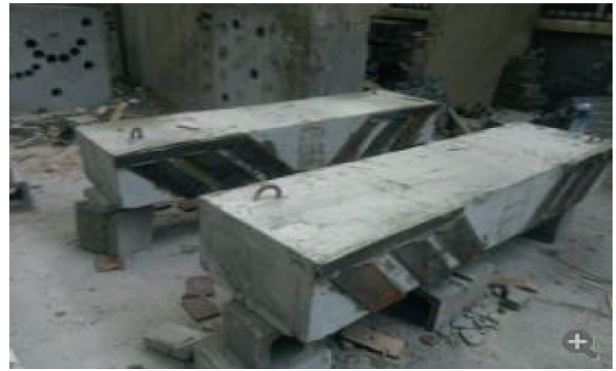

(a)

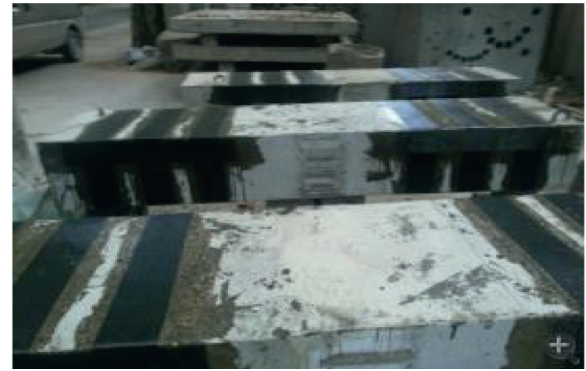

(b)

Figure 5: Reinforcement model: (a) steel plate reinforcement and (b) carbon fiber cloth reinforcement.

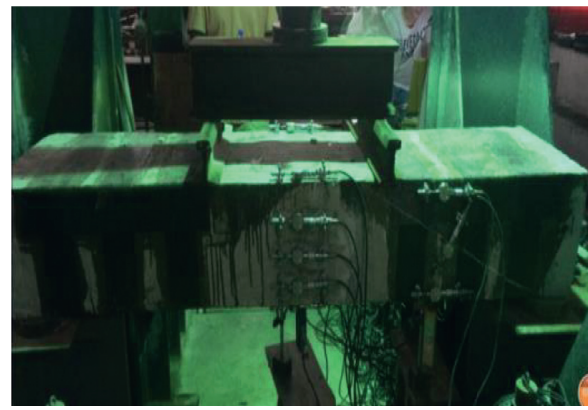

(a)

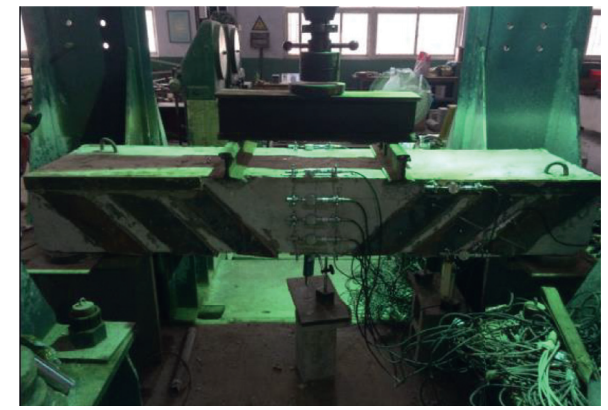

(b)

Figure 6: Static load test of prestressed hollow beam: (a) static load test of carbon cloth reinforcement and (b) steel plate reinforcement static load test.

observed, and the variation law of the deflection and strain during the fatigue process of the test plate was analyzed. Secondly, the fatigue test was performed on the prestressed concrete test hollow slab strengthened by bonded steel and carbon fiber cloth under carbonization. The fatigue characteristics of the two reinforcement methods under carbonized corrosion conditions were tested, and the mechanical properties of the fatigue test process of the reinforcement test plate were also analyzed. The specific effects of carbonation erosion on the fatigue characteristics of two kinds of reinforced methods were investigated.

The fatigue loading device comprised the hydraulic fatigue testing machine. The test plate layout was the same as 
TABLE 4: Fatigue loading test scheme.

\begin{tabular}{lcc}
\hline $\begin{array}{l}\text { Fatigue loading } \\
\text { peak } F_{\max }(\mathrm{kN})\end{array}$ & $\begin{array}{c}\text { Fatigue loading } \\
\text { trough } F_{\min }(\mathrm{kN})\end{array}$ & Frequency $(\mathrm{Hz})$ \\
\hline 200 & 60 & 5 \\
\hline
\end{tabular}

that for the static load test. The stress ratio of the fatigue loading was 0.8 , and the loading frequency was $5 \mathrm{~Hz}$. The specific loading scheme is shown in Table 4.

\subsubsection{Fatigue Test Measurement Content and Instrument Layout}

(1) Strain and Displacement Measurement. Before the start of the fatigue test and after each 500,000 cycles of the fatigue loading, the static load test was performed to record the strain and deflection under each load, and the attenuation law of the static parameters of the test beam with the increase in the fatigue loading was studied. The strain and displacement at the $1 / 2 L$ section was clearly observed and recorded, where $L$ was the length. The strain gauges were evenly arranged along the beam height in the $1 / 2 L$ section. The displacement gauges were arranged at $1 / 2 L, 1 / 4 L$, and beam-ends. The specific arrangement is shown in Figure 7.

(2) Dynamic Strain and Displacement. The dynamic displacement and dynamic strain were measured before the start of the fatigue test and after each 500,000 cycles of the fatigue loading. The dynamic displacement gauge and strain gauge were arranged in the same manner as those in the static loading test, and the system data were collected using a dynamic strain and displacement meter.

(3) Fundamental Frequency and Damping. Before the start of the fatigue test and after each 500,000 fatigue cycles, the basic frequency and damping tests were stopped. The effects of the fatigue loading on the fundamental frequency and damping of the test beam were studied. Three vibrators were arranged at the end of the test beam, and each vibrator was arranged each $500 \mathrm{~mm}$ in the longitudinal direction of the beam. This arrangement is shown in Figure 8.

(4) Crack Development and Width. Based on the static load test results, the fracture observation control point was selected as the shear crack of the test plate support, and the crush crack of the test plate and the vertical crack data of the test plate web were obtained. Once the crack width reaches $0.2 \mathrm{~mm}$, it was considered that the test plate had suffered fatigue damage, and the fatigue test was stopped.

\section{Experiment Analysis}

4.1. Experimental Analysis of Standard Specimen under Carbonization Erosion. Table 5 shows that as the degree of carbonization erosion increases, the compressive strength of the standard test piece gradually increases. Table 6 shows that the elastic modulus of the test piece gradually increases with the increase in the carbonization erosion degree. This is because,

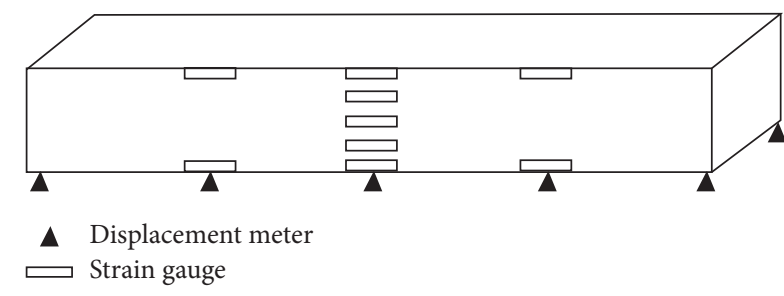

FiguRE 7: Layout of strain gauges and displacement meters.

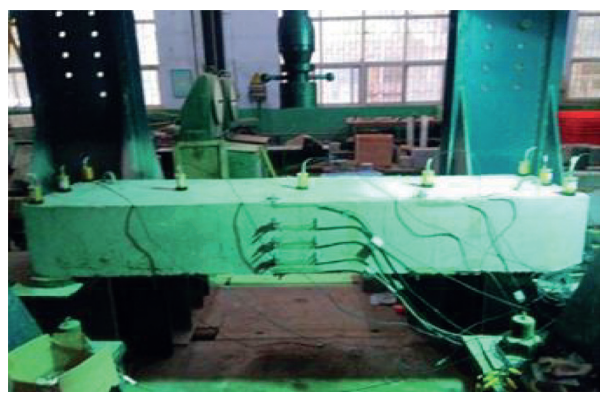

FIGURE 8: Measurement of fundamental frequency and damping.

after the carbonation corrosion of the concrete, the internal void is filled with dense calcification, and the compressive strength and elastic modulus are increased. Furthermore, as the degree of carbonization increases, the compressive strength and elastic modulus increase proportionately.

\subsection{The Influence of Carbonization Erosion on Fatigue Characteristics of Prestressed Hollow Slab}

\subsubsection{The Static Load Failure Test of Prestressed Hollow Slab}

(1) Failure Analysis of Static Load Test. The first crack occurred in prestressed concrete hollow slab beam when it was loaded to $165 \mathrm{kN}$. The main failure location was the prestressed concrete test hollow slab support. The crack mainly appeared at the bearing in the oblique upward $45^{\circ}$ direction. With the gradual increase in the load, the prestressed test plate gradually displayed transverse through cracks, vertical through cracks, oblique end cracks in the beam end, and even cracking of the roof. When loaded to $245 \mathrm{kN}$, the prestressed test hollow slab reached the ultimate bearing capacity failure state, and the maximum crack width was $1.675 \mathrm{~mm}$. The maximum crack width value during loading is shown in Table 7 , and the final failure mode of the test plate is shown in Figure 9.

\section{(2) Stress and Deformation Analysis of Static Load Test.}

(1) Strain analysis: in the static load failure test, the concrete strain along the beam height changes is shown in Figure 10. During the test, with the neutral axis as the boundary line, the tensile strain and compressive strain increased with the increase in the loading level. At the end of the test, the strain increase rate of the concrete increases with the increase in the load. When the load exceeded 
TABLE 5: Compressive strength of standard specimen under carbonization erosion.

\begin{tabular}{|c|c|c|c|c|c|c|c|}
\hline \multirow[t]{2}{*}{ Specimen size $(\mathrm{mm})$} & \multirow[t]{2}{*}{ Strength } & \multicolumn{2}{|c|}{$\begin{array}{l}\text { Precarbonization } \\
\text { strength }(\mathrm{MPa})\end{array}$} & \multicolumn{2}{|c|}{$\begin{array}{l}\text { Strength }(\mathrm{MPa}) \\
\text { (carbonization } \\
\text { depth of } 5 \mathrm{~mm} \text { ) }\end{array}$} & \multicolumn{2}{|c|}{$\begin{array}{l}\text { Strength }(\mathrm{MPa}) \\
\text { (carbonization } \\
\text { depth of } 10 \mathrm{~mm} \text { ) }\end{array}$} \\
\hline & & 53.5 & & 59.4 & & 68.9 & \\
\hline \multirow[t]{2}{*}{$100 \times 100 \times 100$} & C50 & 55.5 & 54.4 & 61.5 & 61.0 & 69.8 & 69.0 \\
\hline & & 54.2 & & 62.0 & & 68.3 & \\
\hline
\end{tabular}

TABLE 6: Elasticity modulus of the standard specimen under carbonization erosion.

\begin{tabular}{|c|c|c|c|c|c|c|c|}
\hline \multirow[t]{2}{*}{ Specimen size $(\mathrm{mm})$} & Strength & \multicolumn{2}{|c|}{$\begin{array}{l}\text { Elastic modulus } \\
\text { (GPa) (before } \\
\text { carbonization) }\end{array}$} & \multicolumn{2}{|c|}{$\begin{array}{c}\text { Elastic modulus } \\
(\mathrm{GPa}) \\
\text { (carbonization } \\
\text { depth of } 5 \mathrm{~mm} \text { ) }\end{array}$} & \multicolumn{2}{|c|}{$\begin{array}{c}\text { Elastic modulus } \\
\text { (GPa) } \\
\text { (carbonization } \\
\text { depth of } 10 \mathrm{~mm} \text { ) }\end{array}$} \\
\hline & & 42.5 & & 51.1 & & 55.2 & \\
\hline \multirow[t]{2}{*}{$100 \times 100 \times 100$} & C50 & 46 & 43.9 & 49.2 & 49.5 & 57.3 & 55.5 \\
\hline & & 43.1 & & 48.3 & & 53.9 & \\
\hline
\end{tabular}

TABLE 7: Crack development of the test beam.

\begin{tabular}{lcccccc}
\hline Cracking load $(\mathrm{kN})$ & 165 & 180 & 200 & 220 & 240 & 245 \\
\hline Crack width $(\mathrm{mm})$ & 0.05 & 0.12 & 0.33 & 0.72 & 0.98 & 1.68 \\
\hline
\end{tabular}

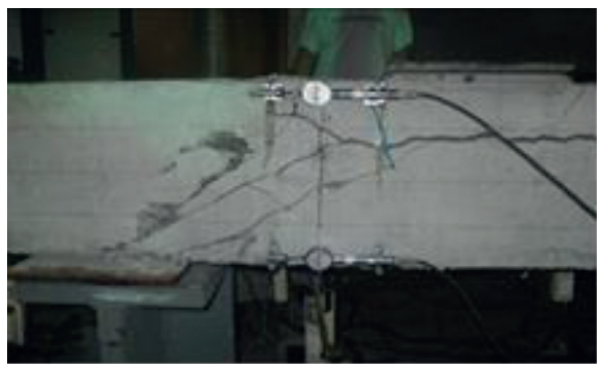

Figure 9: Final failure mode of the test plate by static load.

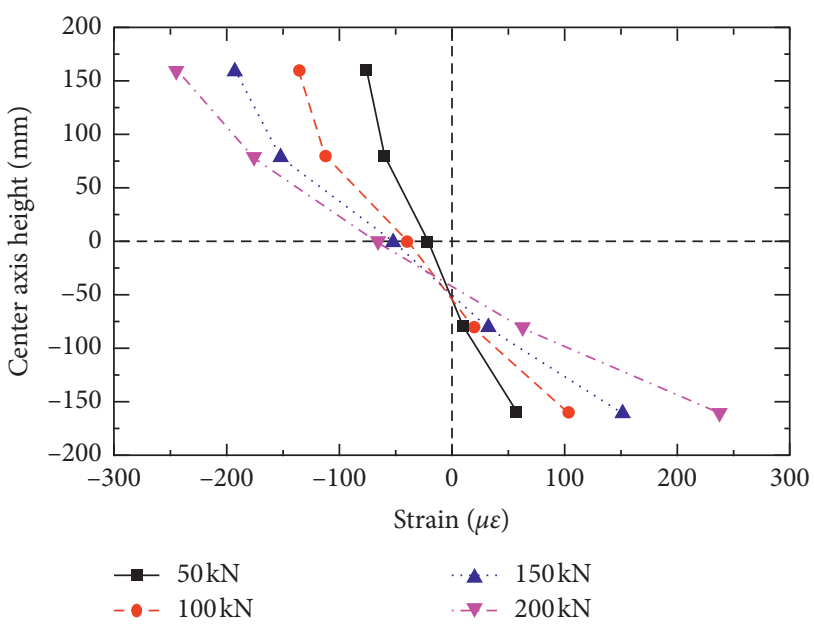

Figure 10: Concrete strain along the cross section.

$200 \mathrm{kN}$, the strain gauge test data were invalid owing to the excessive crack width. From the pretest data, it could be determined that the strain of the concrete along the

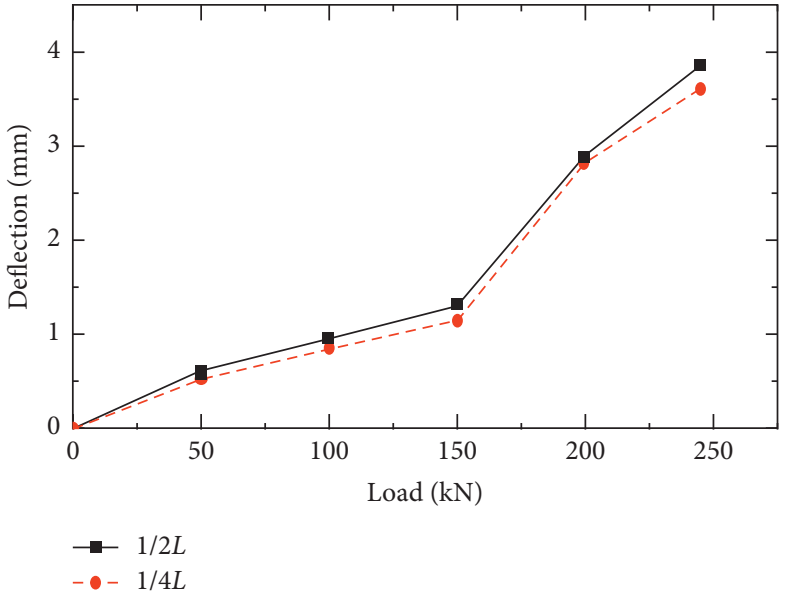

FIGURE 11: Load-deformation curves of static load test.

beam section height was almost linear. As the load increased, the height of the compression zone decreased, the neutralization axis continued to rise, and the stress of the prestressed concrete hollow slab conformed substantially to the flat section assumption.

(2) Deflection analysis: the relationship between the deflection and load at $1 / 4 L$ and $1 / 2 L$ of the test plate during the static loading was shown in Figure 11. Before the crack appeared in the test plate, the deflection at $1 / 4 L$ and $1 / 2 L$ exhibited a steady increase with the increase in the load. However, the difference in deflection at $1 / 4 L$ and $1 / 2 L$ gradually increased, which was consistent with the deflection trend of the prestressed test plate by the method of three-point loading. With the gradual increase in the loading level, cracks gradually appeared in the test plate, and the downward deflection speed increased. When the cracks occur on a large scale, the deflection of the test plate began to gradually slow down owing to the effect of the prestressed steel bar. This trend could be clearly observed in the load-deflection curve of the test plate. 
TABLE 8: Crack development of slab beams under the fatigue test $(\mathrm{mm})$.

\begin{tabular}{lccccccc}
\hline Fatigue times $\left(10^{4}\right)$ & 2 & 5 & 120 & 140 & 160 & 250 & 300 \\
\hline BW & 0 & 0 & 0 & 0 & 0.02 & 0.11 & 0.20 \\
BQ & 0 & 0 & 0.01 & 0.10 & 0.19 & 0.21 & - \\
BZ & 0.01 & 0.25 & - & - & - & - & - \\
\hline
\end{tabular}

\subsubsection{Fatigue Test Analysis of Carbonized Erosion Prestressed Hollow Slab}

(1) Fatigue Failure Analysis of Prestressed Hollow Slabs with Carbonization Erosion. The first crack appeared at the same position of the different carbonization corrosion test slab beams subjected to the fatigue load, and the crack development trend was similar. Table 8 shows the relationship between the maximum crack width and the number of fatigue cycles for the different carbonized corrosion test panels. It can be observed from Table 8 that after the carbonization corrosion, cracks appear earlier with the number of fatigue loading cycles increases, and the crack development speed is significantly greater than that of the healthy components. The fatigue life of the erosion test board decreases significantly, especially for the test plate subjects to severe carbonization corrosion, and the fatigue life was only 50,000 cycles. The more serious the degree of carbonization corrosion, the lower the number of fatigue cycles required for cracks to appear. For example, cracks begin to appear while subjected to 20,000 fatigue cycles for the severe carbonization corrosion test board. After the cracks appear, the crack width increases along with the degree of carbonization corrosion under the same number of fatigue cycles. As the degree of carbonization increases, the number of fatigue cycles required from the occurrence of cracks to the failure of the test plate gradually decreases. The healthy test plates require nearly 1.4 million fatigue cycles to progress from the first appearance of cracks to failure, and the test plates subjected to mild corrosion required less than 1.3 million fatigue cycles, while the test plate subjected to severe carbonization corrosion required only 30,000 fatigue cycles to progress from the first appearance of cracks to fatigue damage.

In summary, as the depth of carbonization increases, the prestressed test panels become larger than the healthy test panels and both in terms of the crack occurrence time and the crack development speed. The cracked model of test plate is shown in Figure 12.

(2) Analysis of Static Strain and Deflection of Carbonized Erosion Prestressed Hollow Slab.

(1) Strain analysis: Figure 13 shows the relation of the tensile strain at the $1 / 2 \mathrm{~L}$ and $1 / 4 \mathrm{~L}$ sections of the test plate as a function of the number of fatigue cycles. As shown in the figure, the tensile strain at $1 / 2 L$ and $1 / 4 L$ of the prestressed test plate gradually increases with the increase of fatigue loadings times. For the same fatigue cycle times, the strain of the carbonization corrosion test plate was less than that of healthy test plate. Before 2 million fatigue cycles, the tensile strain at $1 / 2 L$ of the healthy test plate and the mild carbonization corrosion test plate increased with the increase of fatigue loading times and showed a linearly increasing trend. After fatigue cycle times of the test plate reached 2 million, the strain difference between the two test plates gradually decreased. The original $100 \mu \varepsilon$ gradually reduced to approximately $50 \mu \varepsilon$ when the test plate beam fatigue cycles reached 2.5 million cycles, and the strain difference between the two sets of test plates reached a minimum value. The strain of the severe carbonization test plate increased with the increase in the fatigue frequency, and the strain increases rapidly. From the beginning of the test till the occurrence of damage at nearly 50,000 cycles, the strain increased by $100 \mu \varepsilon$.

(2) Deflection analysis: Figure 14 shows the relationship between the deflection at the $1 / 2 \mathrm{~L}$ and $1 / 4 \mathrm{~L}$ sections of the test plate and the fatigue cycle times. It can be observed from Figure 14 that as the fatigue cycle times increase, the deflection of the test plates at the $1 / 2 \mathrm{~L}$ and $1 / 4 \mathrm{~L}$ sections tends to increase slowly, and under the same fatigue cycles times, the deflection of the test plate gradually decreases with the increase in the degree of carbonization corrosion. The deflection difference between the mild carbonization corrosion test plate and healthy test plate gradually increases with the increase in the fatigue frequency, and the deflection of the slightly carbonized test plate under the same fatigue cycles times is smaller than that of the healthy test plate. From the appearance of cracks till fatigue failure, the crack size of the severely carbonized test panels only increased by $0.126 \mathrm{~mm}$ during the 50,000 -fatigue-cycle process. The test plate with severe carbonization corrosion is prone to brittle failure and poor fatigue resistance.

(3) Dynamic Data Analysis of Carbonized Erosion Prestressed Hollow Slab.

(1) Dynamic strain of test plate under fatigue loading: Figure 15 shows the dynamic strain of the test plate as a function of the carbonization corrosion under the same fatigue cycle times. The dynamic strain of the test plate changes sinusoidally with the fatigue loading process, which is consistent with the actual loading mode. On analyzing the data and integrating the stress data of the different test panels, it can be found that with the carbonization depth increases, the dynamic strain under the same fatigue time gradually decreases.

(2) Transverse displacement of test plate under fatigue loading: the midspan dynamic displacement of the test plate during the fatigue testing is shown in Figures 16 and 17. Under the sinusoidal load, the midspan dynamic displacement of the test plate shows a sinusoidal change. As fatigue cycle times increase, the midspan dynamic displacement of the test plate increases with 


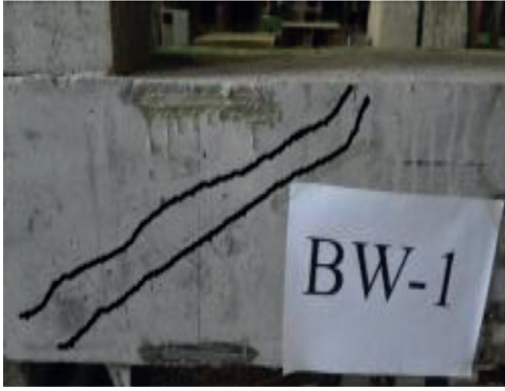

(a)

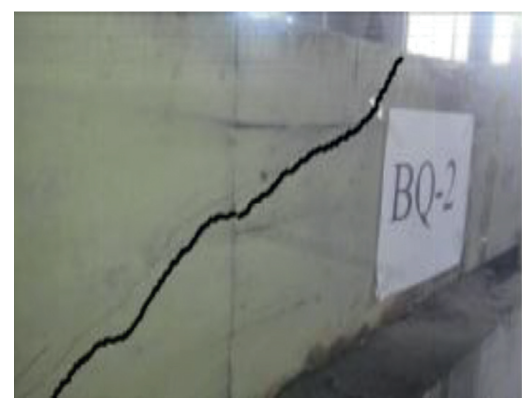

(b)

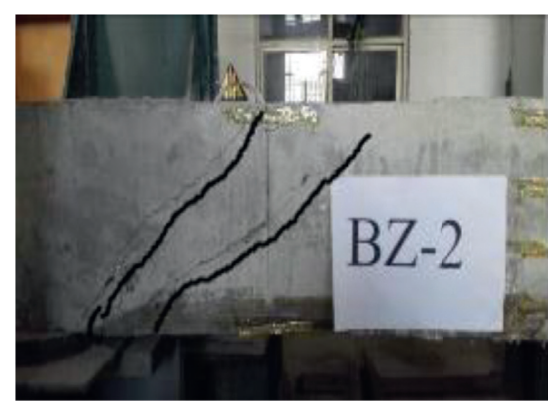

(c)

FIGURE 12: Development of cracks under the fatigue test: (a) BW crack map, (b) BQ crack map, and (c) BZ crack map.

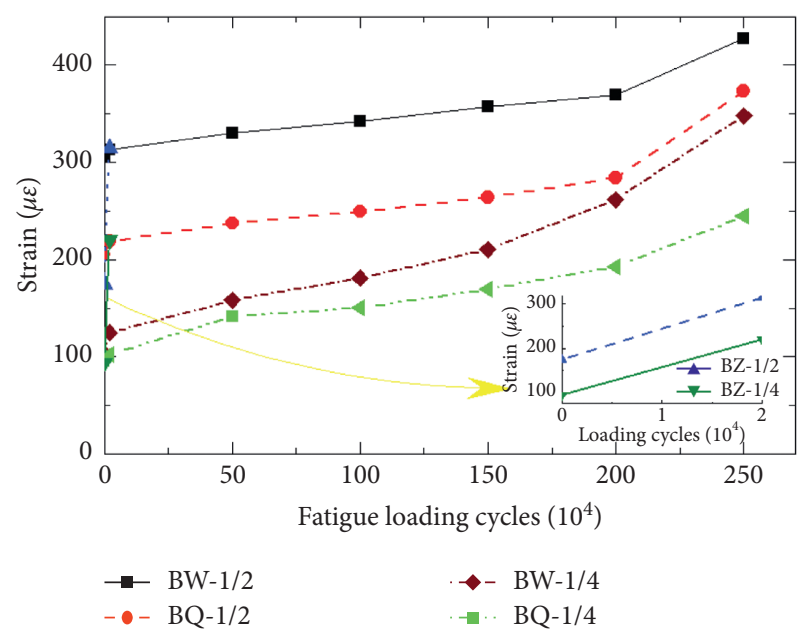

Figure 13: Development of static strain under fatigue testing.

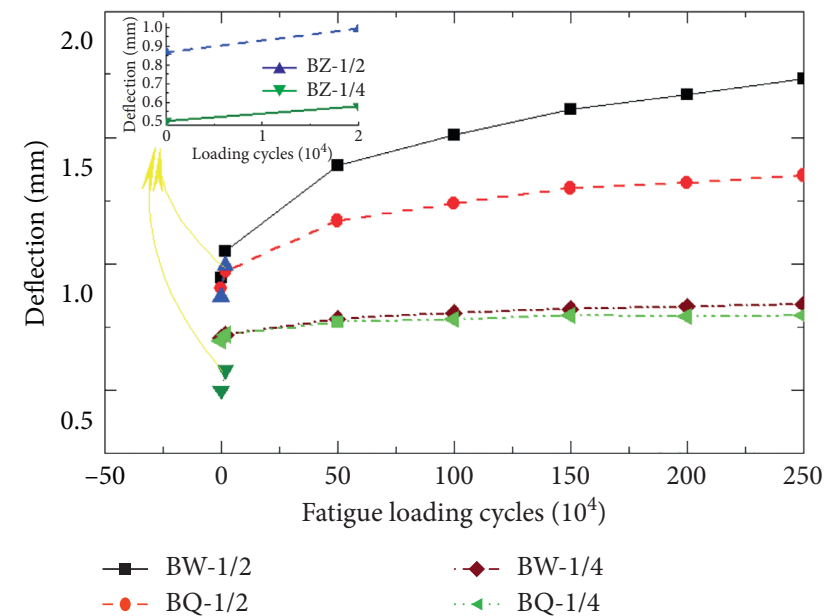

Figure 14: Development of static deflection under fatigue testing.

the same loading. However, as the depth of the carbonization increases, the dynamic displacement of the test plate under the same number of fatigue cycles gradually decreases. The dynamic displacement of the test plate subjected to carbonization is significantly smaller than that of the test plate that is not subjected to carbonization.

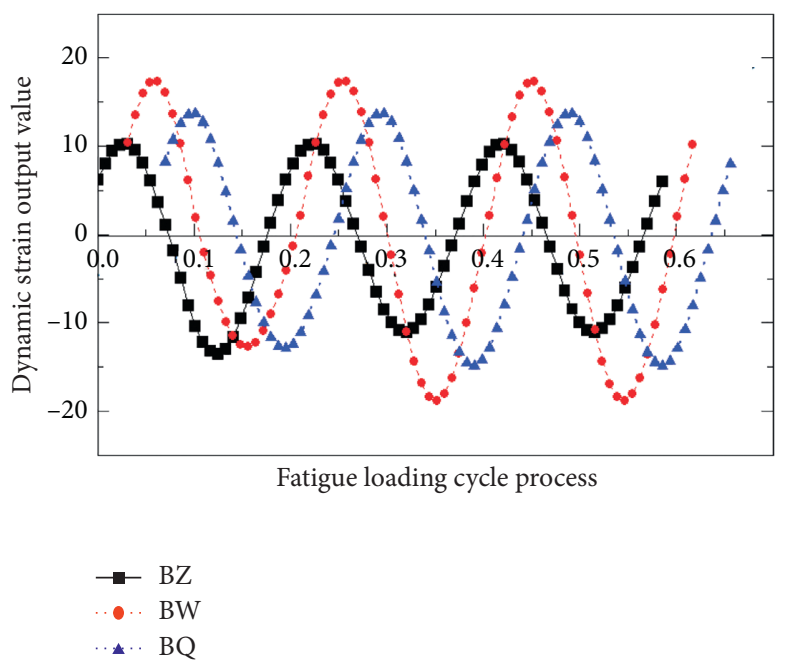

FIGURE 15: Dynamic strain of test plate under fatigue testing.

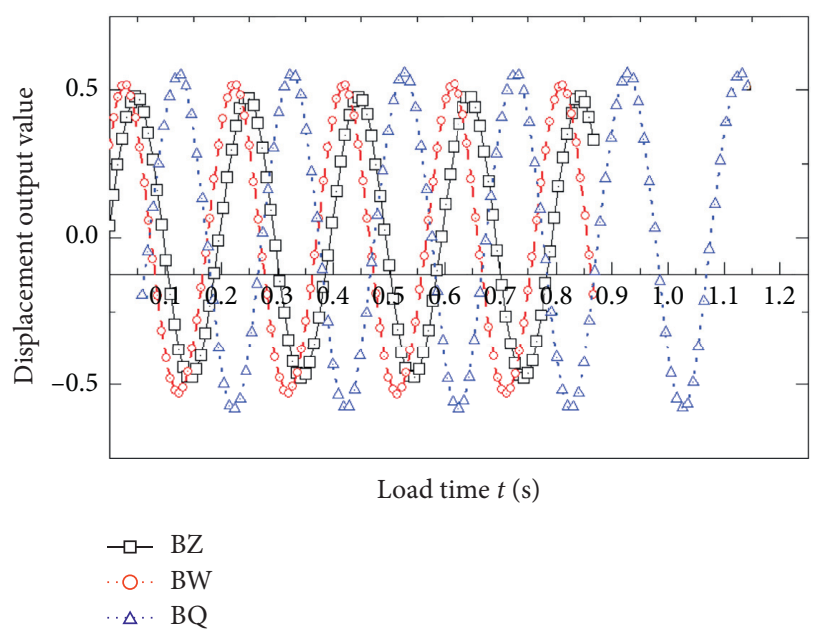

Figure 16: Dynamic displacement of test plate under fatigue loading.

(4) Modal Analysis of Prestressed Hollow Slabs under Carbonization Erosion. The modal data of the test plate under fatigue loading are shown in Figures 18 and 19. The degree of carbonization corrosion influences the natural frequency and damping of the test plate. Before the start of the fatigue 


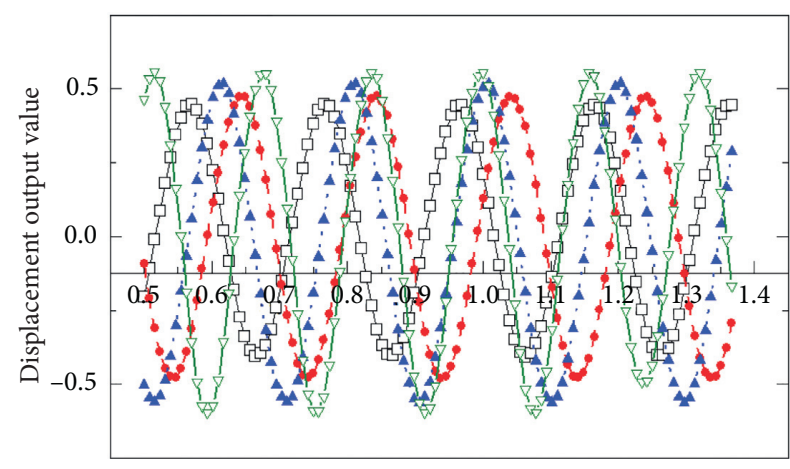

Load time $t(\mathrm{~s})$

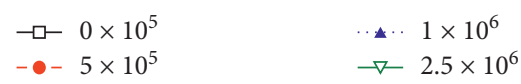

FIgURE 17: Dynamic strain of test plate under fatigue loading.

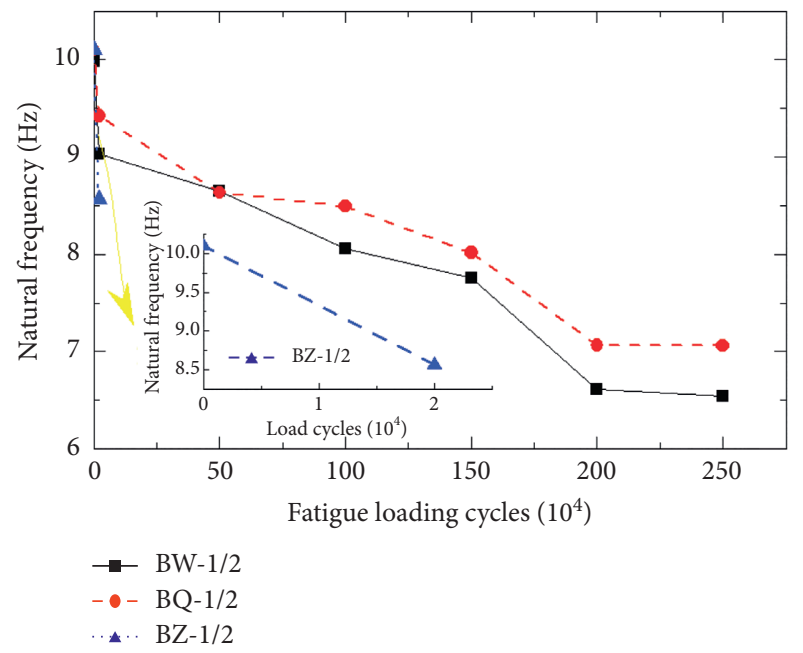

FIGURE 18: Natural frequency of test plate under fatigue loading.

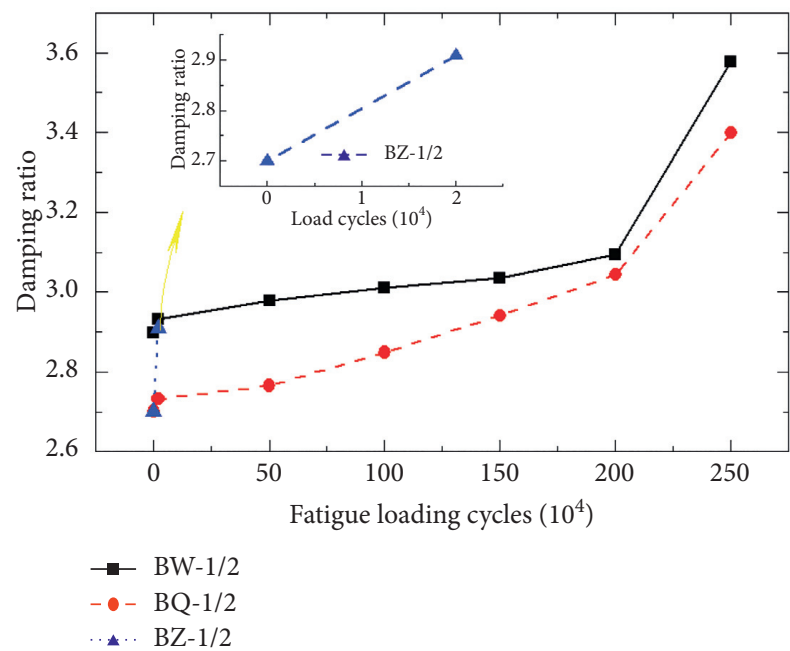

FIGURE 19: Damping ratio of test plate under fatigue loading.

test, the corrosion test plate caused a slight increase in the self-vibration frequency of the healthy test plate. This may be because, after the test plate was carbonized, the capillary channel in the concrete was filled with the reactants of the carbonization reaction, and the concrete integrity was improved. As a result, the stiffness of the plate was increased, and as the fatigue test progresses, the test plate showed tiny cracks, and the stiffness of the test plate decreased. The natural vibration frequency of the mild corrosion test plate was greater than that of the healthy test plate in the fatigue process, and although the self-vibration frequency was slightly increased in the severe corrosion test plate, the stiffness decreased rapidly owing to the earlier crack occurrence during the fatigue process. During the fatigue test, as the tiny cracks appeared in the concrete and developed, the crack interfaced rubbed against each other, caused the damping to increase. Therefore, as compared with the other test components, the heavy carbonization test plate had the fastest rate of increase in damping, which indicated that the fatigue resistance was relatively poor.

\subsection{The Influence of Carbonization Erosion on Fatigue Characteristics of Prestressed Hollow Slab}

4.3.1. Comparative Analysis of Static Load Test of Prestressed Hollow Slab before and after Reinforcement. To verify the reinforcement effect of the test plate strengthened by the bonded steel plate and carbon fiber cloth, the static test was performed on the strengthened test plate. Considering the change in the bearing capacity before and after the test plate is strengthened, the maximum applied load of the test plate is $150 \mathrm{kN}$. The test board included a carbon fiber cloth reinforced and a bonded steel-plate-reinforced test plates. The static load test data before and after reinforcement are shown in Tables 9 and 10.

Under the same load, the deflections of the $1 / 4$ and $1 / 2$ spans of the strengthened carbon-fiber-cloth-reinforced test plate and the bonded steel-plate-reinforced test plate are obviously smaller than that before reinforcement, and under the $150 \mathrm{kN}$ load, the $1 / 2$ span deflection of the carbon-fibercloth-reinforced test plate decreased from $1.18 \mathrm{~mm}$ to $0.80 \mathrm{~mm}$, and the deflection decreased by $31.8 \%$. The $1 / 2$ span deflection of the bonded steel plate test panel decreased from $1.11 \mathrm{~mm}$ to $0.69 \mathrm{~mm}$, and the deflection decreased by $37.1 \%$. Under the same load, the $1 / 2$ span strain of the reinforcement test plate was smaller than that of the test plate before reinforcement, and under the load of $150 \mathrm{kN}$, the compressive strain of the carbon-fiber-cloth reinforcement test plate was reduced by $6.8 \%$, and the tensile strain was reduced by $10.6 \%$. The strain was reduced by $9.02 \%$, and the tensile strain was reduced by $12 \%$. The concrete strain before and after reinforcement showed a nearly linear change with the height of the cross section of the test plate, which proved that the test plates before and after reinforcement satisfied the flat section assumption.

From the comprehensive analysis of the static load data, it can be concluded that both reinforcement methods were beneficial in improving the stress level of the test plate and the rigidity of the test plates were improved. Excluding economic and environmental factors, the deflection of the 
TABLe 9: The comparison of strain and deflection (before and after carbon-fiber reinforcement) under different load.

\begin{tabular}{|c|c|c|c|c|c|c|c|c|}
\hline \multicolumn{5}{|c|}{ Before reinforcement } & \multicolumn{4}{|c|}{ After reinforcement } \\
\hline Load $(\mathrm{kN})$ & $\mathrm{W}-1 / 2(\mathrm{~mm})$ & $\mathrm{W}-1 / 4(\mathrm{~mm})$ & $\mathrm{Y}-1(\mu \varepsilon)$ & $\mathrm{Y}-5(\mu \varepsilon)$ & $\mathrm{W}-1 / 2(\mathrm{~mm})$ & $\mathrm{W}-1 / 4(\mathrm{~mm})$ & $\mathrm{Y}-1(\mu \varepsilon)$ & $\mathrm{Y}-5(\mu \varepsilon)$ \\
\hline 50 & 0.37 & 0.3 & -92.3 & 65.5 & 0.27 & 0.21 & 60.2 & 60.2 \\
\hline 100 & 0.52 & 0.41 & -171.1 & 115.9 & 0.46 & 0.37 & 107.5 & 107.5 \\
\hline 150 & 1.18 & 0.74 & -247 & 170.3 & 0.80 & 0.64 & 152.3 & 152.3 \\
\hline
\end{tabular}

TAвLE 10: The comparison of strain and deflection (before and after bonded steel reinforcement) under different load.

\begin{tabular}{|c|c|c|c|c|c|c|c|c|}
\hline \multicolumn{5}{|c|}{ Before reinforcement } & \multicolumn{4}{|c|}{ After reinforcement } \\
\hline Load $(\mathrm{kN})$ & $\mathrm{W}-1 / 2(\mathrm{~mm})$ & $\mathrm{W}-1 / 4(\mathrm{~mm})$ & $\mathrm{Y}-1(\mu \varepsilon)$ & $\mathrm{Y}-5(\mu \varepsilon)$ & $\mathrm{W}-1 / 2(\mathrm{~mm})$ & $\mathrm{W}-1 / 4(\mathrm{~mm})$ & $\mathrm{Y}-1(\mu \varepsilon)$ & $\mathrm{Y}-5(\mu \varepsilon)$ \\
\hline 50 & 0.37 & 0.3 & -89.05 & 86.1 & 0.31 & 0.24 & -94.65 & 66.4 \\
\hline 100 & 0.52 & 0.4 & -217.75 & 153.9 & 0.50 & 0.35 & -181.7 & 123.3 \\
\hline 150 & 1.11 & 0.73 & -288.75 & 215.5 & 0.69 & 0.58 & -262.2 & 189.5 \\
\hline
\end{tabular}

Note. W-1/2: midspan deflection, W-1/4: quarter span deflection value, Y-1: compressive strain at the top of the midspan, and Y-5: tension strain at the bottom of the midspan.

steel-plate-reinforced test beam is higher than that of the carbon fiber cloth.

\subsubsection{Comparative Analysis of Fatigue Test for Reinforced Prestressed Hollow Slab}

(1) Fatigue Experiment Process of Carbon-Fiber-ClothReinforced Test Plate. The prestressed hollow slabs strengthened by the method of the carbon fiber cloth effectively inhibited the development of the original cracks, and the crack development in the fatigue process was slow. Before the start of fatigue cycles, the original crack reached $0.22 \mathrm{~mm}$, and after 500,000 cycles, the crack width reached $0.28 \mathrm{~mm}$. And after 1 million fatigue cycles, the maximum crack width increased to $0.3 \mathrm{~mm}$ and a new tiny crack appeared in oblique section shears. When the fatigue cycle times reached 2 million cycles, the maximum width of the crack at the fulcrum of the original support reached $0.35 \mathrm{~mm}$. The fatigue test crack is shown in Figure 20, and the fatigue test data are shown in Table 11.

(2) Fatigue Experiment Process of Bonded Steel-Plate-Reinforced Test Plate. The fatigue test was performed on the test plate reinforced with bonded steel, and the test phenomenon during the fatigue process was observed. The original crack was restrained by the oblique bond steel during the fatigue process, and the original crack expanded slightly. The steel plate greatly inhibited the development of cracks. After the reinforcement, the test plate could withstand 2 million fatigue cycles. After 2 million fatigue cycles, the midspan deflection under the action of $200 \mathrm{kN}$ was $1.43 \mathrm{~mm}$. The fatigue test data are shown in Table 12.

(3) Fatigue Test Analysis of Test Plate Strengthened without Erosion. The deflection and strain of the reinforcement members increased with the increase in the fatigue frequency, and the growth trend was relatively stable. It was proved that during the fatigue process, some fatigue damage occurred inside the reinforcement test plate, and the fatigue damage accumulated continuously. During the 2 million-time fatigue cycles, the deflection of the member

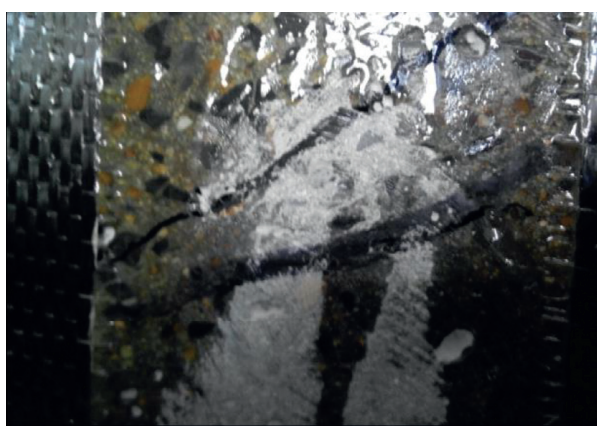

FIgURE 20: The cracks under the 1.2 million fatigue load test.

TABLE 11: The relation between deflections and strain and fatigue loading times for carbon-fiber-reinforced plate under the $200 \mathrm{kN}$ load.

\begin{tabular}{lccc}
\hline Fatigue times $\left(10^{4}\right)$ & $\mathrm{Y}-5(\mu \varepsilon)$ & $\mathrm{Y}-1(\mu \varepsilon)$ & $\mathrm{W}-1 / 2(\mathrm{~mm})$ \\
\hline 0 & 208.8 & -290.3 & 1.06 \\
50 & 221.7 & -290.3 & 1.12 \\
100 & 237.6 & -307.1 & 1.29 \\
150 & 247.1 & -337.3 & 1.33 \\
200 & 260.3 & -362.3 & 1.44 \\
\hline
\end{tabular}

Note. W-1/2: midspan deflection, Y-1: compressive strain at the top of the midspan, and Y-5: tension strain at the bottom of the midspan.

TABLE 12: The relation between deflections and strain and fatigue loading times for a bonded steel-plate-reinforced plate under the $200 \mathrm{kN}$ load.

\begin{tabular}{lccc}
\hline Fatigue cycles $\left(10^{4}\right)$ & $\mathrm{Y}-5(\mu \varepsilon)$ & $\mathrm{Y}-1(\mu \varepsilon)$ & $\mathrm{W}-1 / 2(\mathrm{~mm})$ \\
\hline 0 & 216.5 & -217.9 & 1.11 \\
50 & 225.7 & -241.3 & 1.18 \\
100 & 241.6 & -260.1 & 1.28 \\
150 & 253.1 & -290.3 & 1.35 \\
200 & 258.3 & -325.6 & 1.43 \\
\hline
\end{tabular}

Note. W-1/2: midspan deflection, Y-1: compressive strain at the top of the midspan, and Y-5: tension strain at the bottom of the midspan.

reinforced with carbon fiber cloth increased from $1.06 \mathrm{~mm}$ to $1.44 \mathrm{~mm}$ under the load of $200 \mathrm{kN}$, and the reinforcement member of the bonded steel plate increased from $1.11 \mathrm{~mm}$ to 


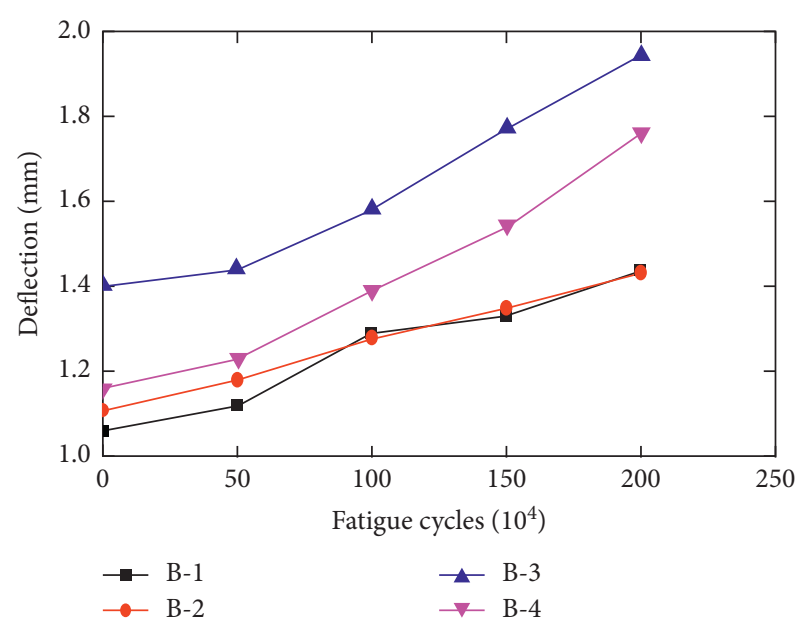

FIGURE 21: The relation between deflection and fatigue cycle times for different test beams.

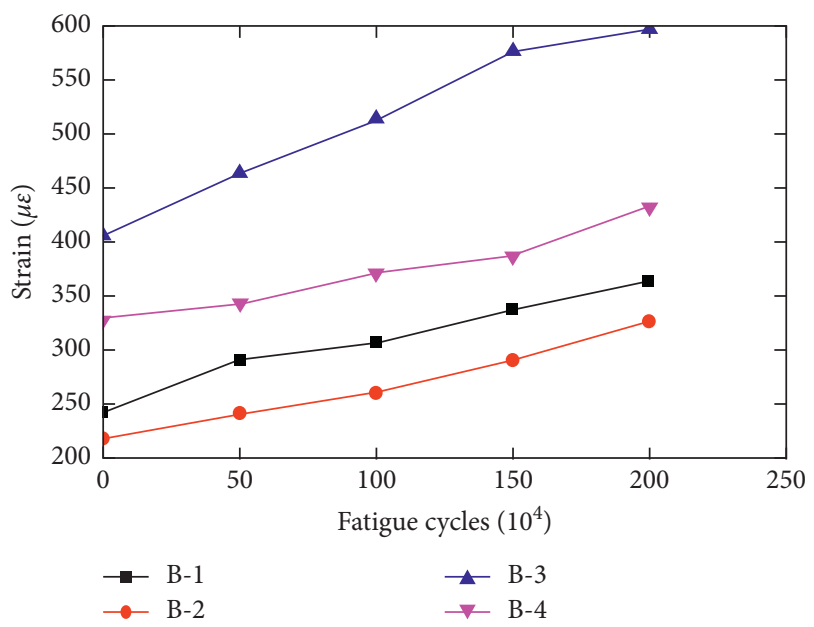

FIgURE 22: The relation between midspan compressive strain and fatigue cycle times for different test beams.

$1.43 \mathrm{~mm}$, which met the deflection limit under normal use. The types of reinforcement methods were beneficial to improving the stress level of the test plate, the rigidity of the test plate was improved, and better fatigue resistance was obtained.

The two reinforcement methods are compared below. Figures 21-23 show that the deflection of the bonded carbon-fiber-reinforced plate is less than the deflection of the bonded steel reinforced members during 0 to 1 million fatigue cycles. During the 1 to 2 million fatigue cycles, the deflection of the bonded carbon-fiber-reinforced member is close to that of the bonded steel reinforced member. The compressive strain of the bonded carbon-fiber-reinforced member is higher than that of the bonded steel reinforced member during the fatigue process. The tensile strain of the bonded steel reinforced member is higher than that of the carbon-fiber-reinforced member before 1.5 million fatigue cycles and is close to that of the carbon-fiber-reinforced member after 1.5 to 2 million fatigue cycles. Excluding

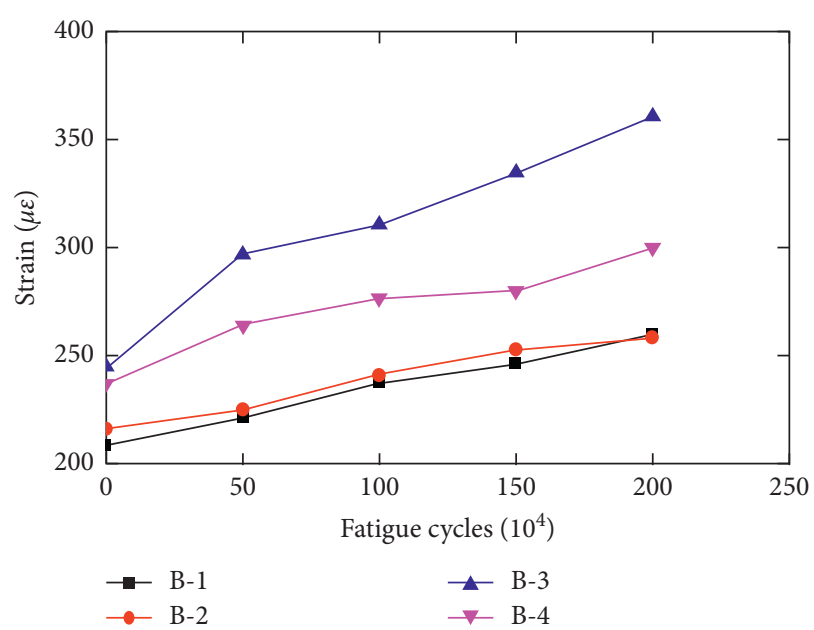

FIGURE 23: The relation between midspan tensile strain and fatigue cycle times for different test beams. B-1: uneroded carbon-fiberreinforced test plate, B-2: uneroded bonded steel-plate-reinforced test plate, B-3: carbonized eroded carbon-fiber-reinforced test plate, and B-4: carbonized eroded bonded steel-plate-reinforced test plate.

economic and environmental factors, the improvement of the deflection and strain amplitude of the test plate under the fatigue load is slightly better than that of the carbon fiber cloth.

\subsubsection{Fatigue Test Analysis of Prestressed Hollow Slabs Strengthened by Carbonization}

(1) Fatigue Test of Carbonized Erosion Carbon-Fiber-ClothReinforced Test Plate. Before the fatigue test, the maximum crack width of the reinforced member was $0.21 \mathrm{~mm}$. During the fatigue test, the structural cracks can be clearly observed in the loading and unloading process, which indicated that the structural reinforcement effect was lost owing to the carbonization erosion. After 500,000 times of cycles of fatigue loading of 0.8 stress ratios, the maximum crack width reached $0.26 \mathrm{~mm}$, and the maximum crack developed to $0.31 \mathrm{~mm}$ after 1 million-time fatigue cycles, and a slight crack appeared in the oblique section at 800,000 cycles. After 2 million cycles, the crack width reached $0.13 \mathrm{~mm}$, and after 2 million fatigue cycles, the maximum crack of the reinforcing member reached $0.38 \mathrm{~mm}$. It was found that the deflection of the reinforced members increased slowly in the early stage, and the deflection increased by $0.25 \mathrm{~mm}$ from 0 to 1 million fatigue cycles. The deflection of the test plate increased rapidly in the late stage of the fatigue loading, and the deflection increased by $0.45 \mathrm{~mm}$ during the 1 million to 2 million fatigue cycles. This was because, as the times of fatigue cycles increased, the reinforcement effect was gradually lost, and the deflection increased significantly. The fatigue test process data are shown in Table 13.

(2) Fatigue Test of Carbonized Erosion Bonded Steel-PlateReinforced Test Plate. In the fatigue loading process of bonded steel reinforced members, the increase in the original cracks was effectively suppressed. The original 
TABle 13: The relation between deflections and strain and fatigue loading times for carbon-fiber-reinforced plate (corroded by carbonization) under the $200 \mathrm{kN}$ load.

\begin{tabular}{lccc}
\hline Fatigue cycles $\left(10^{4}\right)$ & Y-5 $(\mu \varepsilon)$ & Y-1 $(\mu \varepsilon)$ & W-1/2 $(\mathrm{mm})$ \\
\hline 0 & 212.2 & -323.2 & 1.021 \\
50 & 237.4 & -365.8 & 1.124 \\
100 & 261.5 & -393.4 & 1.278 \\
150 & 290.6 & -425.6 & 1.401 \\
200 & 314.7 & -466.2 & 1.724 \\
\hline
\end{tabular}

Note. W-1/2: midspan deflection, Y-1: compressive strain at the top of the midspan, and Y-5: tension strain at the bottom of the midspan.

TABLE 14: The relation between deflections and strain and fatigue loading times for steel-plate-reinforced plate (corroded by carbonization) under the $200 \mathrm{kN}$ load.

\begin{tabular}{lccc}
\hline Fatigue cycles $\left(10^{4}\right)$ & Y-5 $(\mu \varepsilon)$ & Y-1 $(\mu \varepsilon)$ & W-1/2 $(\mathrm{mm})$ \\
\hline 0 & 254.5 & -360.7 & 1.09 \\
50 & 274.1 & -375.9 & 1.13 \\
100 & 286.9 & -390.9 & 1.40 \\
150 & 291.3 & -410.2 & 1.52 \\
200 & 308.2 & -440.3 & 1.88 \\
\hline
\end{tabular}

Note. W-1/2: midspan deflection, Y-1: compressive strain at the top of the midspan, and Y-5: tension strain at the bottom of the midspan.

cracks can hardly be seen during the test. As compared with the reinforcement members, the original cracks did not appear under the fatigue load. The phenomenon of the combination showed that the method of bonded steel plate reinforcement had a good inhibitory effect on crack development. Similar to healthy components and uneroded reinforced components, the tensile strain of test plate increased with the increase of the times of fatigue cycles, and this increase was small. The midspan deflection increased slowly in the early stage and increased rapidly in the later stage of the loading. After 2 million cycles of fatigue loading, the midspan deflection reached $1.88 \mathrm{~mm}$. The fatigue test process data are shown in Table 14.

(3) Stress Analysis of Fatigue Process of Carbonized Erosion Bonded Reinforced Test Plate. Before and after the carbonization erosion test: the crack propagation form of the two reinforcement members was similar to that of the healthy reinforcement member. Under the action of 2 million-time fatigue cycles, the maximum crack of the carbon-fiber-cloth reinforcement member increases from $0.21 \mathrm{~mm}$ to $0.38 \mathrm{~mm}$, which increase by $0.17 \mathrm{~mm}$. The increase in the crack width was $0.13 \mathrm{~mm}$, which was not subjected to the erosion strengthening member, which was not much different. However, the cracks of the reinforced steel plate members had hardly developed, which indicated that the carbonization erosion had only a slight effect on the fatigue crack resistance of the reinforced members, and both the reinforcement methods have a good fatigue crack resistance.

Figures 21-23 show that the deflection of the reinforcement members increases gradually during the fatigue process, and the increase rate is faster during the 50-200 million cycles of fatigue loading. It is found that the deflection of the carbon-fiber-reinforced member is greater than that of the bonded steel reinforced member during the fatigue loading process. The strain of the bonded carbon fiber and the bonded steel reinforcement member increases rapidly in the late fatigue loading stage, and the strain of the bonded carbon-fiber reinforcement member is larger than that of bonded steel reinforcement member. Excluding economic and environmental factors, the method of bonded steel plate reinforcement in the environment of carbonization erosion provides better results than carbon fiber reinforcement in the improvement of deflection and strain amplitude of the fatigue damage test panels.

\subsubsection{Analysis of Dynamic Data of Reinforcement Test Plates} under Carbonization. Table 15 shows the dynamic displacement of the test plate under the action of 2 million fatigue load cycles. The dynamic displacement of the tested plate after erosion is significantly greater than that of the test plate without erosion. The dynamic displacement of the test plate reinforced with carbon fiber cloth is slightly greater than that of the test plate with the bonded steel plate. Table 16 shows the change in the dynamic displacement growth rate of the test plate under the action of 2 million fatigue load cycles. The dynamic displacement growth rate of the viscose fiber cloth is greater than the dynamic displacement growth rate of the bonded steel plate as compared with the uneroded reinforcement member. It displays that the impact resistance performance of the test plate after environmental erosion is significantly weaker than that of the uneroded reinforcement member under the fatigue load, and the impact resistance of the test plate strengthened by the bonded steel plate is better than that of the test plate reinforced with the carbon fiber cloth.

\subsubsection{Analysis of Modal Data of Reinforced Test Plates under Carbonization Erosion}

(1) Fundamental frequency analysis: it can be clearly observed from Table 17 that, as the number of fatigue cycles increases, the natural vibration frequency of the test plate decreases, which indicates that the fatigue 
TABLE 15: Trend of dynamic displacement of test plates under 2 million fatigue cycles.

\begin{tabular}{lcccc}
\hline Degree of erosion & Reinforcement method & Crest $(\mathrm{mm})$ & Trough $(\mathrm{mm})$ & Amplitude $(\mathrm{mm})$ \\
\hline Not eroded & Carbon fiber cloth & 0.39 & -0.32 & 0.71 \\
Not eroded & Sticky steel plate & 0.37 & -0.33 & 0.71 \\
Carbonization & Carbon fiber cloth & 0.53 & -0.52 & 1.05 \\
Carbonization & Sticky steel plate & 0.52 & -0.51 & 1.03 \\
\hline
\end{tabular}

TABle 16: Dynamic displacement growth rate of test plates under 2 million fatigue load cycles.

\begin{tabular}{lcccc}
\hline Degree of erosion & Reinforcement method & Crest $(\mathrm{mm})$ & Trough $(\mathrm{mm})$ & Amplitude $(\mathrm{mm})$ \\
\hline Not eroded & Carbon fiber cloth & 1 & 1 & 1 \\
Not eroded & Sticky steel plate & 1 & 1 & 1 \\
Carbonization & Carbon fiber cloth & $35.90 \%$ & $62.50 \%$ & $47.89 \%$ \\
Carbonization & Sticky steel plate & $40.54 \%$ & $54.55 \%$ & $45.07 \%$ \\
\hline
\end{tabular}

Note. The dynamic displacement data under the 2 million fatigue cycle test of the uneroded test plate are set as 1 .

TABle 17: Trend of modal of test plates under different fatigue cycles.

\begin{tabular}{lcccccc}
\hline Degree of erosion & Reinforcement method & 0 million cycles & 0.5 million cycles & 1 million cycles & 1.5 million cycles & 2.0 million cycles \\
\hline Not eroded & Carbon fiber cloth & 4.8 & 3.1 & 2.7 & 2.7 & 2.3 \\
Not eroded & Sticky steel plate & 5.2 & 3.4 & 2.9 & 2.7 & 2.5 \\
Carbonization & Carbon fiber cloth & 5 & 3.1 & 2.9 & 2.7 & 2.4 \\
Carbonization & Sticky steel plate & 5.3 & 3.5 & 3 & 2.8 & 2.6 \\
\hline
\end{tabular}

TABLE 18: The relation between damping and fatigue loading times for reinforced plate corroded by carbonization.

\begin{tabular}{lcccccc}
\hline Degree of erosion & Reinforcement method & 0 million cycles & 0.5 million cycles & 1 million cycles & 1.5 million cycles & 2.0 million cycles \\
\hline Not eroded & Carbon fiber cloth & 5.23 & 6.42 & 5.75 & 6.25 & 6.48 \\
Not eroded & Sticky steel plate & 5.01 & 5.31 & 5.43 & 5.54 & 6.01 \\
Carbonization & Carbon fiber cloth & 5.3 & 5.43 & 5.44 & 5.74 & 6.32 \\
Carbonization & Sticky steel plate & 4.92 & 5.15 & 5.33 & 5.47 & 6.43 \\
\hline
\end{tabular}

damage inside the reinforcement test plate is continuously accumulated as the times of fatigue cycles increase. The overall stiffness of the test panel gradually decreases as the number of fatigue cycles increases. Under the same fatigue frequency, the natural vibration frequency of the test plate subjected to carbonization erosion is significantly greater than that of the uneroded test plate. This is because that the concrete reacts chemically to form a dense calcification after the carbonization of the reinforcement test plate, which results in the overall test plate. It becomes more compact, the overall performance of the test board increases, and the natural frequency increases. For the same test panel, the fundamental frequency of the bonded steel plate reinforcement member is larger than that of the carbon-fiber-cloth reinforcement member under the same number of fatigue cycles. In terms of overall performance, irrespective of whether the test plate is corroded, the overall performance of the bonded steel plate reinforcement member during the fatigue loading is superior to that of the carbon-fibercloth-reinforced member.

(2) Damping analysis: from Table 18, it is observed that the damping of the test plate tends to increase gradually during the fatigue process. This is because, as the times of fatigue cycles increase, the fatigue damage inside the test plate continues to accumulate, and the damage cracks inside the test plate continuously rub against each other. Furthermore, as the times of fatigue cycles increase, the friction between the cracks increases, leading to the test. The vibration of the plate attenuates at a faster rate, and the damping increases with the increase in the times of fatigue cycles. The increase in the damping of the test plate is small during the 2 million fatigue cycles test, and the overall crack development is slower. The reinforcement effect is demonstrated, and the fatigue crack resistance of the test plate after reinforcement is greatly improved. The damping value of the fatigue test process of the reinforcement test plate was analyzed. Under the same fatigue frequency, the damping value of the test plate reinforced with the carbon fiber cloth is greater than that by the steel-plate-reinforced plate. This shows that from the macroscopic point of view, the fatigue damage of the carbon-fiber-reinforced member is greater than the fatigue damage of the reinforced steel plate, which is consistent with the crack development observed in the testing. 


\section{Conclusion}

In this paper, the effects of the carbonation erosion on the fatigue characteristics of prestressed hollow plates and reinforced plated were studied systematically. The main conclusions are as follows:

(1) The axial compressive strength and elastic modulus for the uncarbonized test specimen were $54.4 \mathrm{MPa}$ and $43.9 \mathrm{GPa}$, for the light carbonized erosion test specimen were $61.0 \mathrm{MPa}$ and $49.5 \mathrm{GPa}$, and for the severe carbonized corrosion test piece were $69.0 \mathrm{MPa}$ and $55.5 \mathrm{GPa}$, respectively. Comparison to the healthy components, the axial compressive strength and elastic modulus of the severely carbonized test pieces increased by $26.8 \%$ and $26.4 \%$, respectively.

(2) Before reinforcement:

(1) Static characteristics: in the early stage of the fatigue test, the strain of the carbonized corrosion plate is smaller than that in the healthy test plate. When the fatigue damage state is approached, the strain increase rate of the carbonized corrosion test plate is higher than that of the healthy plate, and the damage is close to or greater than that of the healthy test plate. Under the same times of fatigue loading cycles, the deflection of the carbonized corrosion test plate is less than that of the healthy component, and the gap between the two increases with the fatigue loading. Based on the experimental analysis, it is found that if the compressive strength, elastic modulus, and static index (strain and deflection) are used as indicators to evaluate the health of carbonized erosion components, the ideal conclusions will be drawn, which would be inconsistent with the actual health state of the structure and the fatigue life of the components.

(2) In terms of dynamic characteristics: with the increase in the carbonization degree, the dynamic strain and displacement of the test plate show an antigrowth trend, and as the degree of carbonization corrosion increases, the natural frequency of the test plate increases, and the damping decreases. (3) Fatigue characteristics: after the carbonation corrosion of the prestressed concrete hollow slab, the crack occurrence time and development speed are faster than the healthy test slab, which results in significant deterioration of the fatigue life of the carbonized corrosion component and, especially, the fatigue life of the severe carbonization test plate. Fractures began to occur in the healthy components at 1.6 million fatigue cycles, and more than 1.4 million fatigue cycles occurred between the appearances of cracks to damage. The slightly corroded test panels began to crack after 1.2 million fatigue loading cycles, and nearly 1.3 million fatigue cycles occurred from the appearance of cracks to damage. The test plate subjected to severe carbonization corrosion began to crack after 20,000 fatigue loading cycles, and only 30,000 fatigue cycles occurred from the appearance of cracks to damage.

(3) After reinforcement:

(1) Static characteristics: as compared with the test plates which not subjected to carbonization corrosion before reinforcement, the deflection of the bonded steel test panels is reduced by $10 \%$ to $40 \%$, and the strain is reduced by $10 \%$ to $20 \%$. The test plate strengthened with carbon fiber cloth reduces in deflection of $10 \%-30 \%$ and in strain of $5 \%-20 \%$. The increase in the deflection and strain of the bonded steel plate is better than that which reinforced by carbon fiber cloth. The experimental results show that both reinforcement methods have good reinforcement effects.

(2) In terms of dynamic characteristics: the dynamic displacement of the reinforced members after carbonization is significantly greater than that of the uneroded reinforcement members, and the dynamic displacement of the fiber reinforcement members is greater than that of bonded steel reinforcement members. The impact resistance of the test panel after carbonization is significantly lower than that of the uneroded reinforcement member. As the times of fatigue cycles increase, the natural vibration frequency of the reinforced member decreases, and the damping increases. Under the same fatigue frequency, the natural vibration frequency of the carbonized erosion strengthening member is significantly higher than that of the uneroded reinforcement member. The damping of the uneroded reinforced members increases with the increase in the number of fatigue cycles. After carbonization, the damping increases of the member strengthened by the method of bonded steel plate is greater than that of bonded carbon fiber cloth method, and the corresponding growth rate increases sharply after 1.5 million-time fatigue cycles.

(3) Antifatigue performance analysis: the reinforced members under carbonization erosion can withstand 2 million fatigue loading cycles and have good fatigue resistance. Both the bonded steel plate and carbon fiber cloth methods can effectively inhibit crack development. The cracks in the test plate strengthened using the carbon fiber cloth method are slow to propagate, and new cracks are fewer, while no new cracks are observed in the test plate strengthened using the bonded steel plate method. For the uneroded reinforcement test plates, the deflection and strain increase during the fatigue process are relatively stable, and the erosion reinforcement test panels grow faster in the late stage of fatigue loading. Under the same fatigue frequency, the deflection and strain of the carbonized corrosion strengthen test plate are greater than that of 
uneroded test plate. The steel plate reinforcement members have better mechanical properties and fatigue resistance than the carbon-fiber-reinforced members.

\section{Data Availability}

The data used to support the findings of this study are included within the article.

\section{Conflicts of Interest}

The authors declare that there are no conflicts of interest regarding the publication of this article.

\section{Acknowledgments}

This work was supported by the National Natural Science Foundation of China (no. 51878623), Science and Technology Tackling Project of Henan Science and Technology Agency (no. 172102210500), General Science and Technology Tackling Project of Zhengzhou City (no. 153PKJGG095), Program for Young Backbone Teachers in Colleges and Universities in Henan (no. 2018GGJS005), and Foundation for Postdoctoral Students in Henan Province (no. 1901024).

\section{References}

[1] Editorial Department of China Journal of Highway and Transport, "Review on China's bridge engineering research 2014," China Journal of Highway and Transport, vol. 27, no. 5, pp. 1-96, 2014.

[2] W. Jin and Y. Zhao, "State-of-the-art on durability of concrete structures," Journal of Zhejiang University (Engineering Science), vol. 36, no. 4, pp. 27-36, 2002.

[3] X. Liu, "Fundamental research on safety and durability of major structures in civil and hydraulic engineering," China Civil Engineering Journal, vol. 34, no. 6, pp. 1-7, 2001.

[4] S. Xu, The Models of Deterioration and Durability Evaluation of Reinforced Concrete Structure, Xi'an University of Architecture and Technology, Xi'an, China, 2003.

[5] S. He, Experimental Studies on Durability of Reinforced Concrete Members in Chloride Environment, Dalian University of Technology, Dalian, China, 2004.

[6] T. Cheewaket, C. Jaturapitakkul, and W. Chalee, "Concrete durability presented by acceptable chloride level and chloride diffusion coefficient in concrete: 10-year results in marine site," Materials and Structures, vol. 47, no. 9, pp. 1501-1511, 2014.

[7] Y. Dong, Experimental Research on Durability of Concrete under Sulfate Attack, Zhejiang University, Hangzhou, China, 2011.

[8] Z. Jin, Durability and Service Life Prediction of Concrete Exposed to Harsh Environment in West China, Southeast University, Nanjing, China, 2006.

[9] Y. Zheng, H. Guo, and X. Ning, "Deparment of civil engineering and department of applied mathematics," Journal of China \& Foreign Highway, vol. 37, no. 6, pp. 125-133, 2017.

[10] W. Jin, Q. Lu, Y. Zhao et al., "Research progress on the durability design and life prediction of concrete structures," Journal of Building Structure, vol. 28, no. 1, pp. 7-13, 2007.
[11] J. Berger, S. Z. Bruschetini-Ambro, and J. Kollegger, "An innovative design concept for improving the durability of concrete bridges," Structural Concrete, vol. 12, no. 3, pp. 155-163, 2011.

[12] G. Nganga, M. Alexander, and H. Beushausen, "Practical implementation of the durability index performance-based design approach," Construction and Building Materials, vol. 45, pp. 251-261, 2013.

[13] A. Lotfy, K. M. A. Hossain, M. Lachemi, and M. Lachemi, "Durability properties of lightweight self-consolidating concrete developed with three types of aggregates," Construction and Building Materials, vol. 106, pp. 43-54, 2016.

[14] C. Du, Y. Zheng, Y. Cai et al., "Fatigue characteristics of prestressed hollow slab under carbonation corrosion," Journal of Zhengzhou University (Engineering Science), vol. 39, no. 1, pp. 12-18, 2018.

[15] Y. Zheng, G. Yu, and Y. Pan, "Investigation of ultimate strengths of concrete bridge deck slabs reinforced with GFRP bars," Construction and Building Materials, vol. 28, no. 1, pp. 482-492, 2012.

[16] Y. Wang, D. Niu, and Y. Miao, "Durability of steel fiber reinforced concrete under the combined effects of carbonization and acid rain erosion," Journal of Building Materials, vol. 17, no. 4, pp. 579-585, 2014.

[17] Y. Zheng, Y. Cai, G. Zhang, and H. Fang, "Fatigue property of basalt fiber-modified asphalt mixture under complicated environment," Journal of Wuhan University of TechnologyMaterials Science Edition, vol. 29, no. 5, pp. 996-1004, 2014.

[18] A. Fang, Z. Pan, R. Ma et al., "New development of mesoscopic research on durability performance of structural concrete in bridge," China Journal of Highway and Transport, vol. 29, no. 11, pp. 42-48, 2016.

[19] U. M. Angst and R. Polder, "Spatial variability of chloride in concrete within homogeneously exposed areas," Cement and Concrete Research, vol. 56, no. 2, pp. 40-51, 2014.

[20] J. Jiang, W. Sun, Z. Jin et al., "Service life prediction of structural concrete under coupled interactions of fatigue loading and carbonation factor," Journal of Building Materials, vol. 13, no. 3, pp. 30-35, 2010.

[21] Q. Zhao, H. Xu, and G. Yan, "Influence of stress damage on carbonation of concrete," Journal of Building Materials, vol. 16, no. 3, pp. 503-507, 2013.

[22] H. Lu, Research of the Degeneration of Bearing Capacity of Prestressed Concrete Bridges, Zhengzhou University, Zhengzhou, China, 2014.

[23] R. Neves, F. A. Branco, and J. de Brito, "A method for the use of accelerated carbonation tests in durability design," Construction and Building Materials, vol. 10, no. 36, pp. 585-561, 2012.

[24] S. P. Arredondo-Rea, R. Corral-Higuera, J. M. GomezSoberon et al., "Carbonation rate and reinforcing steel corrosion of concretes aggregates and supplementary cementing materials," International Journal of Lectrochemical Science, vol. 7, no. 2, pp. 1602-1610, 2012.

[25] J. Wang, D. Xiaosong, and Z. Jian, "Durability of CFRP strengthened concrete structure," Concrete, vol. 10, pp. 16-19, 2014.

[26] Y. Yin, Study on the Durability of CFRP Reinforced Concrete Structure under Chloride Environment, Qingdao Technological University, Qingdao, China, 2014.

[27] F. Yan and Z. Lin, "Bond durability assessment and long-term degradation prediction for GFRP bars to fiber-reinforced concrete under saline solutions," Composite Structures, vol. 161, pp. 393-406, 2017. 
[28] A. Altalmas, A. El Refai, and F. Abed, "Bond degradation of basalt fiber-reinforced polymer (BFRP) bars exposed to accelerated aging conditions," Construction and Building Materials, vol. 81, pp. 162-171, 2015.

[29] K. Zhang, L. Ye, and Q. Yue, "Experimental study on flexural fatigue behavior of RC beams strengthened with prestressed CFRP sheets," Industrial Construction, vol. 8, pp. 13-19, 2005.

[30] Y. Chen and Z. Lu, "Design method of RC beam confined with CFRP sheets under bending moment according to fatigue behavior," Building Structure, vol. 36, no. 3, pp. 28-30, 2006.

[31] W. Zhang, L. Song, and X. Gu, "Fatigue performance of corroded RC beams strengthened with carbon fiber composite sheets," China Civil Engineering Journal, vol. 7, pp. 43-50, 2010.

[32] R. Capozucca and M. Nilde Cerri, "Static and dynamic behaviour of RC beam model strengthened by CFRP-sheets," Construction and Building Materials, vol. 16, no. 2, pp. 91-99, 2002.

[33] C. Gheorghiu, P. Labossière, and J. Proulx, "Response of CFRP-strengthened beams under fatigue with different load amplitudes," Construction and Building Materials, vol. 21, no. 4, pp. 756-763, 2007.

[34] Y. Gan, Shear Behavior of Reinforced Concrete Beams Strengthened with Anchored Steel Sheets, Zhengzhou University, Zhengzhou, China, 2006.

[35] J. Zhang, J. Ye, and W. Yao, "Fatigue behavior of the reinforced concrete beam strengthened with steel plate or CFRP," Building Structure, vol. 2, pp. 392-394, 2010.

[36] A. Zhai, Z. Sun, and F. Yaoqi, "Experimental study on fatigue properties of concrete beams strengthened with bonded steel plates," Journal of Qingdao Institute of Architecture and Engineering, vol. 3, pp. 7-11, 2002.

[37] J. Yang, Similarity Principle and Structural Model Test, Wuhan University of Technology Press, Wuhan, China, 2005.

[38] GB/T 50082-2009 Standard for Test Methods of Long-Term Performance and Durability of Ordinary Concrete.

[39] Y. Zheng, P. Yang, Y. Cai et al., "Large size carbonization tank for easy handling of samples," Chinese Patent CN105510216A, 2016. 